\title{
Aspectos ecológicos de Aphidius colemani Viereck (Hymenoptera: Aphidiidae) sobre a população de Sitobion avenae (Fabricius) (Hemiptera: Aphididae) na cultura de trigo em Medianeira, PR
}

\author{
Ecological aspects of Aphidius colemani Viereck (Hymenoptera: \\ Aphidiidae) on the Sitobion avenae (Fabricius) (Hemiptera: Aphididae) \\ population in wheat culture in Medianeira, $P R$.
}

\author{
Agostinho Zanini ${ }^{1 *}$; Luis F.A. Alves² ; Ayres de Oliveira Menezes Júnior ${ }^{3}$; \\ Tânia Mari Vicentini Prestes ${ }^{4}$
}

\begin{abstract}
Resumo
Os afídeos foram o principal problema dos cereais de inverno na década de 70, no Sul do Brasil, havendo necessidade de controle químico para evitar as perdas. Com base no fraco desempenho dos parasitóides nativos, em 1978 foram introduzidas 14 espécies de parasitóides exóticos no Brasil e em 1984, implantouse o Programa de Controle Biológico no Oeste do Estado do Paraná, que proporcionou redução das populações de afídeos e da aplicação de produtos químicos. No entanto, não foram encontrados na bibliografia estudos referentes aos aspectos ecológicos dos parasitóides e de controle biológico de afídeos na região Oeste do Paraná, na cultura de trigo, motivo pelo qual se desenvolveu este estudo. Foram realizadas avaliações semanais em 25 parcelas com $25 \mathrm{~m}^{2}$, coletando-se 100 plantas de trigo, retirando-se das mesmas os afídeos e as múmias. Verificou-se a presença de uma única espécie de afídeo, Sitobion avenae (Fabricius) (Hemyptera: Aphididae), o parasitóide primário Aphidius colemani Viereck (Hymenoptera: Aphidiidae) e hiperparasitóides, verificando-se também a presença de predadores. O pico populacional de $S$. avenae ocorreu no início da floração e as múmias apareceram uma semana após aos afídeos. O controle dos afídeos foi considerado eficiente com $95 \%$ de parasitismo. O pico populacional de A. colemani ocorreu no início de agosto, enquanto dos hiperparasitóides ocorreu na semana seguinte. O crescimento da população de afídeos foi influenciado significativamente pela umidade relativa do ar, enquanto que a população de parasitóide foi influenciada pela temperatura e pela densidade populacional dos pulgões.

Palavras-chave: Insecta, dinâmica populacional, parasitóides
\end{abstract}

\footnotetext{
1 Professor do Centro Federal de Educação Tecnológica do Paraná, Medianeira, PR. E-mail: agozanini@yahoo.com.br

2 Universidade Estadual do Oeste do Paraná/CCBS, Laboratório de Zoologia. Cascavel, PR. E- mail: 1faalves@unioeste.br

3 Universidade Estadual de Londrina, CCA, Departamento de Agronomia. Londrina, PR. E- mail: ayres@uel.com.br

4 Bolsista de Produtividade em pesquisa/CNPq.

* Autor para correspondência.
} 


\begin{abstract}
Aphids were the main winter-cereal problem in the 70's in southern Brazil and it was necessary to use chemical control to avoid losses. Based in the weak performance of native parasites, 14 species of exotic parasites were introduced in 1978, and in 1984 the West of Paranà's Biological Control Program was implanted. This program propitiated the reduction of the Aphid population as well as chemical applications in the field. However, no bibliographic study was found referring to the ecological aspects of the parasites nor about Aphid's biological control in Western Paraná's region wheat production motivating the development of this study. Week evaluations in 25 parcel of $25 \mathrm{~m}^{2}$ were performed where 100 wheat plants were collected, from which aphid and bugs were taken out. It was observed the presence of an Aphid specie, Sitobion avenae (Fabricius) (Hemyptera: Aphididae), the primary parasite Aphidius colemani Viereck (Hymenoptera: Aphidiidae), and hyper parasitoids, and also the presence of predators. S. avenae population zenith occurred in the beginning of budding and bugs appeared a week after the aphids. Aphid control was considered efficient at $95 \%$ total parasitism. Population zenith of $A$. colemani occurred in the beginning of August, while hyper parasitoids zenith occurred the following week. Aphid population growth was significantly influenced by the air relative humidity, whereas parasite population was influenced by temperature and aphid population density.
\end{abstract}

Key words: Insect, population dynamic, parasites

\section{Introdução}

Os afídeos causaram perdas significativas na cultura do trigo no Brasil, na década de 70, quando atingiam níveis populacionais elevados no Rio Grande do Sul e no Paraná, atingindo cerca de 200 indivíduos por planta (KOBER, 1972; PIMENTA; SMITH, 1976). Na tentativa de controlar o ataque destes insetos eram utilizados inseticidas de amplo espectro de ação, com até três aplicações, trazendo sérios prejuízos à saúde humana, ao meio ambiente, e aos insetos benéficos, proporcionando o aumento das populações das pragas (GASSEN; TAMBASCO, 1983a; SALVADORI, 1999).

Assim, em 1978 foi estabelecido, no Brasil, o programa de controle biológico de afídeos do trigo com a introdução de 14 espécies de himenópteros, já que os parasitóides nativos mostraram-se incapazes de controlar a praga. Tais insetos foram multiplicados e liberados em diferentes regiões tritícolas do país, reduzindo as populações de afídeos e a aplicação de inseticidas (SALVADORI; SALLES, 2002). Até 1982 haviam sido liberados aproximadamente 3,8 milhões de parasitóides, sendo observada a adaptação de Aphidius uzbekistanicus Luzhetzki sobre o pulgão Sitobion avenae, Aphidius rhopalosiphi De Stefani e Praon volucre (Haliday) para os pulgões S. avenae e Metopolophium dirhodum (Walker), sendo que parasitando os pulgões do gênero Rhopalosiphum e Schizaphis, Aphidius colemani (Fabricius) foi mais comumente encontrado (GASSEN; TAMBASCO, 1983b).

Apesar da dinâmica populacional dos afídeos ser influenciada pelas condições climáticas, os inimigos naturais são os agentes mais importantes, sendo os parasitóides mais específicos pois, ao realizarem a postura no interior do corpo do pulgão causam a sua morte, mas há poucos estudos sobre o assunto (GASSEN; TAMBASCO, 1983a; GASSEN, 1986; VALENCIA; TRILLOS, 1986; KRING; KRING, 1988). Assim o objetivo do trabalho foi obter informações referentes aos aspectos ecológicos dos parasitóides e de controle biológico de afídeos na região Oeste do Paraná, na cultura de trigo.

\section{Material e Métodos}

O trabalho foi realizado na fazenda Slongo, na linha Thomé, município de Medianeira, PR (25 $18^{\circ}$ $30,7^{\prime \prime}$ S e 54 03' 17,4" W com 464 metros de altitude), no período de maio a setembro de 2003 .

O plantio foi realizado no sistema convencional, com a variedade de trigo COODETEC 105, no dia 18 de maio de 2003 (espaçamento de $20 \mathrm{~cm}$ entre linhas, com densidade de 45 plantas/m), em uma área 
total de 7,0 hectares, delimitada pelas culturas de milho safrinha, aveia e pastagens.

Instalou-se o experimento no centro da referida área, com a dimensão de $625 \mathrm{~m}^{2} \mathrm{e}$ bordadura de no mínimo $100 \mathrm{~m}$ de cada lado. A área experimental foi sub-dividida em 25 parcelas de $5 \times 5 \mathrm{~m}$, totalizando $25 \mathrm{~m}^{2}$. Neste local não houve aplicação de produtos fitossanitários, sendo que o controle de ervas daninhas foi realizado pelo método de capina manual.

O acompanhamento das populações de pulgões e de parasitóides ocorreu durante o desenvolvimento da cultura do trigo, com início em 19 de junho, por meio de amostragens semanais com a coleta de 4 plantas de forma aleatória em cada parcela, perfazendo um total de 100 plantas em toda a área experimental. As amostras foram colhidas a partir da instalação do experimento até o estádio palha seca, adotando-se a escala desenvolvida por Feeckes (1941), para acompanhamento da fenologia da planta do trigo em cada data.

As plantas de cada parcela foram cortadas na base do colmo, rente ao solo, com a utilização de tesoura, acondicionadas em sacos plásticos transparentes e transportadas ao Laboratório de Biologia do CEFET/PR (Centro Federal de Educação Tecnológica do Paraná), em Medianeira. Os pulgões foram retirados das plantas com auxílio de pincel, colocados sobre cartolina de cor branca e examinados sob microscópio estereoscópico com aumento de até 20 vezes. Em seguida, foram contabilizados e separaram-se adultos ápteros e alados, ninfas e os indivíduos parasitados (múmias).

Em seguida, os pulgões foram acondicionados em frascos devidamente identificados, contendo álcool $70 \%$ para a sua conservação, os quais foram enviados para identifição por especialistas pelas Professoras Dra. Sonia M. N. Lazzari e Dra. Regina C. Zonta de Carvalho, do Departamento de Zoologia da Universidade Federal do Paraná e depositados na coleção do Laboratório de Controle Biológico, UNIOESTE, Campus de Marechal Cândido Rondon. As múmias, depois de contadas, foram isoladas individualmente em cápsulas gelatinosas transparentes e guardadas em placas de Petri, devidamente identificadas, mantidas sob a condição ambiente, a fim de permitir o desenvolvimento e a emergência dos parasitóides e hiperparasitóides para posterior identificação, que foi realizada pelo Professor Dr. Ayres de Oliveira Menezes Jr., da Universidade Estadual de Londrina (UEL) e depositados na coleção do Laboratório de Entomologia, Centro de Ciências Agrárias, UEL.

Mediu-se um metro na linha das plantas de forma aleatória, em cada parcela da área experimental e verificou-se a presença de insetos predadores sendo que, na ausência dos mesmos distribuiu-se novamente a trena, em uma nova parcela. Quando se constatou a presença de insetos predadores identificou-se no nível de família comparando-se com Gassen (1986).

Os dados meteorológicos referentes à precipitação pluviométrica, umidade relativa do ar e temperatura máxima e mínima foram obtidos da estação meteorológica do CEFET-Medianeira, PR, distante aproximadamente $9 \mathrm{~km}$ do local do experimento.

A dinâmica populacional foi analisada com base em análise gráfica e de correlação linear simples, entre o número de insetos (pulgões, parasitóides e predadores) por amostragem semanal e a média dos fatores climáticos semanais (umidade relativa do ar, precipitação pluviométrica e temperatura), utilizandose o programa Microsoft Excel ${ }^{\circledR}$.

\section{Resultados e Discussão}

Registrou-se apenas a ocorrência de Sitobion avenae (Fabricius) e verificou-se que sua população surgiu na lavoura no final do mês de junho, crescendo de forma gradativa durante as seis semanas iniciais, atingindo pico populacional no período em que a cultura estava na fase de floração, decrescendo de forma acentuada nas últimas cinco semanas das 13 observadas (Tabela 1). 
Tabela 1. Número e total de Sitobion avenae ninfas e adultos ápteros e alados coletados semanalmente em 100 plantas de trigo, de junho a setembro de 2003, Medianeira, PR

\begin{tabular}{lcccc}
\hline Semana & Ninfas & Adultos ápteros & Adultos alados & Total de afídeos \\
\hline 19/jun & 0 & 0 & 0 & 0 \\
26/jun & 0 & 0 & 1 & 1 \\
03/jul & 3 & 7 & 1 & 11 \\
10/jul & 20 & 11 & 0 & 31 \\
17/jul & 41 & 18 & 4 & 63 \\
24/jul & 21 & 56 & 3 & 80 \\
31/jul & 51 & 72 & 3 & 126 \\
07/ago & 68 & 112 & 5 & 185 \\
14/ago & 32 & 48 & 2 & 82 \\
21/ago & 7 & 19 & 4 & 30 \\
28/ago & 1 & 3 & 0 & 4 \\
04/set & 0 & 1 & 0 & 1 \\
11/set & 0 & 0 & 0 & 0 \\
Total & 244 & 347 & 23 & 614 \\
\hline
\end{tabular}

No entanto, Rabbinge, Ankersmit e Pak (1979) registraram na Holanda um crescimento mais rápido da população de $S$. avenae nas três primeiras semanas das seis em que foram realizadas as coletas nos meses de maio/junho/julho, dobrando a população, a cada três dias, sendo que no final da terceira semana ocorreu um rápido colapso da população. Esse mesmo modelo de crescimento repetiu-se nos anos de 1975, 1976 e 1977 em que se realizou o estudo. Além disso, observaram pico populacional dessa espécie na primavera, no final de junho até o início de julho.
Embora o resultado da análise de correlação entre pulgões e temperaturas máxima e mínima não tenha sido significativa, observou-se que a temperatura média do período do ciclo da cultura foi propícia para o desenvolvimento dos afídeos $\left(17^{\circ} \mathrm{C}\right.$ a $\left.20^{\circ} \mathrm{C}\right)$, pois segundo Valencia e Trillos (1986) e Salvadori (1999) a temperatura ideal para proliferação dos afídeos situa-se entre 18 e $24^{\circ} \mathrm{C}$ (Figura 1) (Tabela 2). Corroborando a afirmação, Apablaza e Tiska (1973) registraram, no Chile, populações máximas de afídeos na cultura do trigo no mês de outubro, com temperatura média de $17^{\circ} \mathrm{C}$.

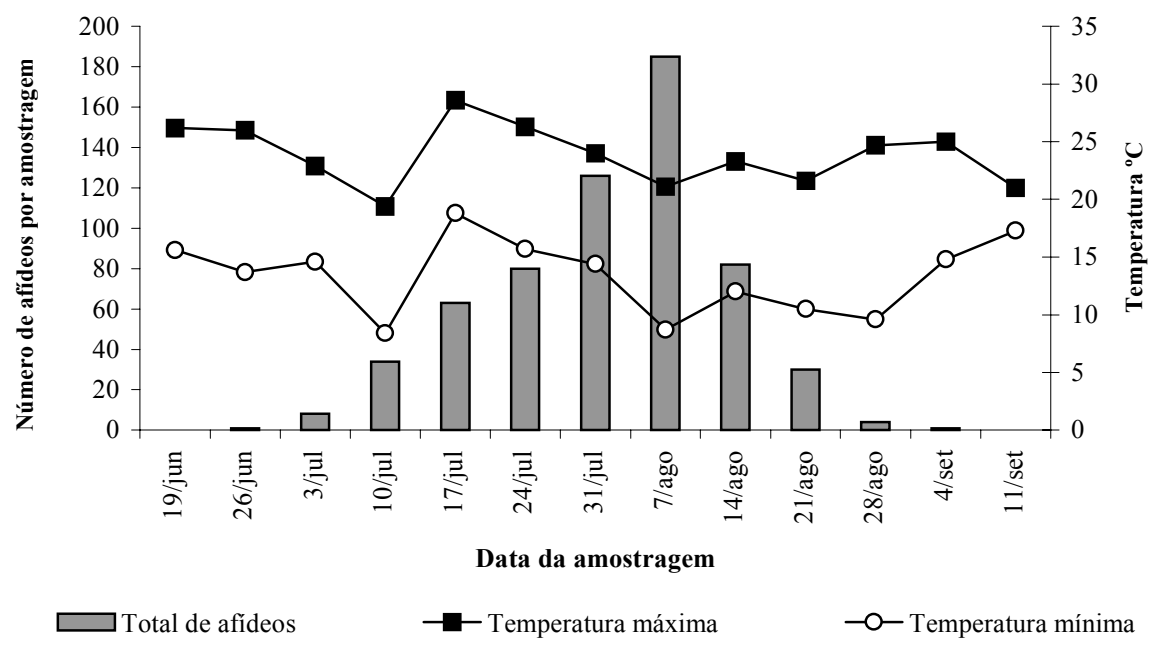

Figura 1. Flutuação populacional de Sitobion avenae e dados médios semanais de temperatura máxima e mínima, de junho a setembro de 2003, na cultura do trigo em Medianeira, PR. 
Tabela 2. Coeficientes de correlação encontrados entre fatores ambientais e o número de Sitobion avenae, parasitóides, predadores e interações obtidos de coletas realizadas semanalmente em 100 plantas de trigo, de junho a setembro de 2003, Medianeira, PR.

\begin{tabular}{cc}
\hline Fatores ambientais & Coeficientes de correlação $(\mathbf{r})$ \\
\hline Pulgões & $-0,10656^{\mathrm{ns}}$ \\
Precipitação pluvial $(\mathrm{mm})$ & $-0,14347^{\mathrm{ns}}$ \\
Temperatura máxima $\left({ }^{\circ} \mathrm{C}\right)$ & $-0,25691^{\mathrm{ns}}$ \\
Temperatura Mínima $\left({ }^{\circ} \mathrm{C}\right)$ & $-0,61538^{*}$ \\
Umidade relativa do ar $(\%)$ & \\
Parasitóides & $-0,28011^{\mathrm{ns}}$ \\
Precipitação pluvial $(\mathrm{mm})$ & $-0,32446^{* *}$ \\
Temperatura máxima $\left({ }^{\circ} \mathrm{C}\right)$ & $-0,60181^{*}$ \\
Temperatura Mínima $\left({ }^{\circ} \mathrm{C}\right)$ & $-0,03734^{\mathrm{ns}}$ \\
Umidade relativa do ar $(\%)$ & \\
Predadores & $-0,18783^{\mathrm{ns}}$ \\
Precipitação pluvial $(\mathrm{mm})$ & $0,02661^{\mathrm{ns}}$ \\
Temperatura máxima $\left({ }^{\circ} \mathrm{C}\right)$ & $-0,11355^{\mathrm{ns}}$ \\
Temperatura Mínima $\left({ }^{\circ} \mathrm{C}\right)$ & $-0,54099^{* *}$ \\
Umidade relativa do ar $(\%)$ & \\
Interação & $0,60401^{*}$ \\
Pulgões/parasitóides & $0,85064^{*}$ \\
Pulgões/predadores & $0,70669^{*}$ \\
Hiperparasitóide/parasitóide & \\
\hline
\end{tabular}

${ }^{*} 0,6 \leq(\mathrm{r}) \leq 1$ variáveis de correlação significativa; ${ }^{* *} 0,3 \leq(\mathrm{r}) \leq 0,6$ correlação relativamente fraca entre as variáveis $\mathrm{e}^{\text {ns }} 0$ $\leq(\mathrm{r}) \leq 0,3$ correlação muito fraca entre as variáveis.

No que diz respeito à ocorrência de picos populacionais de afídeos, resultados semelhantes ao trabalho realizado foram obtidos por Mendes et al. (2000), que verificaram o afídeo Therioaphis trifilii (Monell) na cultura de alfafa, no mês junho, com temperatura em torno de $17^{\circ} \mathrm{C}$.
No período do desenvolvimento da cultura não ocorreram geadas e as precipitações pluviométricas foram baixas, com média mensal de 74,4mm. Em conseqüência, a umidade relativa também foi baixa $(33 \%)$, verificando-se que esta influenciou significativamente a infestação de pulgões na cultura, fato comprovado pelo resultado da análise de correlação ( $\mathrm{r}=-0,61538)$ (Tabela 2) (Figura 2). 


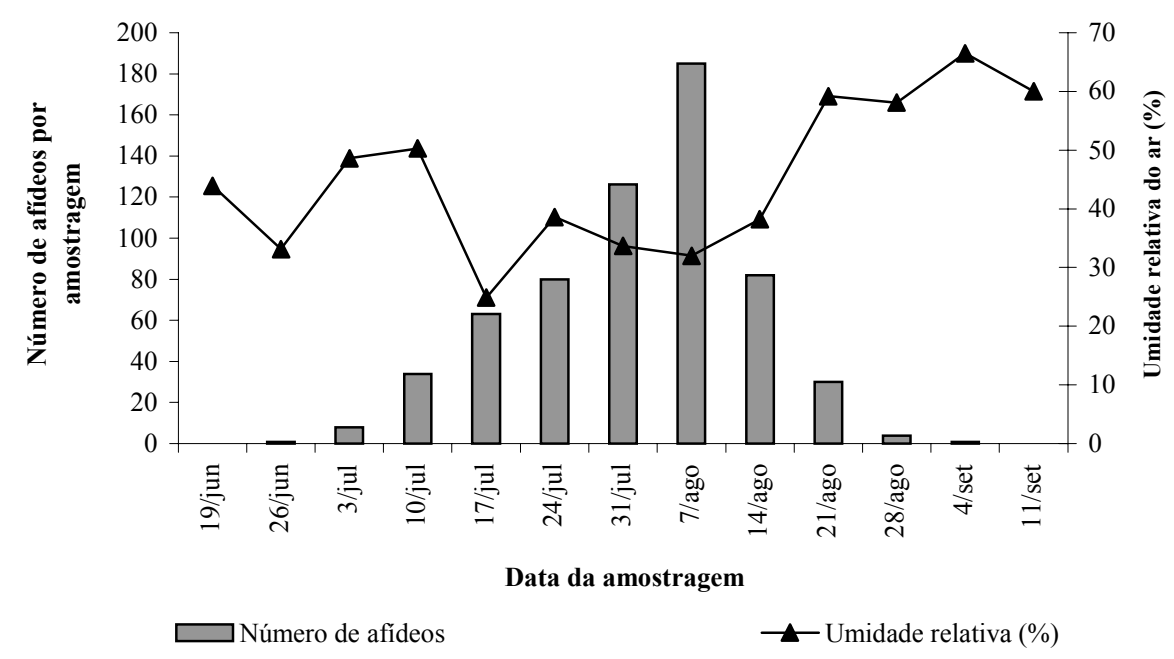

Figura 2. Flutuação populacional de Sitobion avenae e médias semanais de umidade, de junho a setembro de 2003, na cultura do trigo em Medianeira, PR.

Em virtude da ausência de tais interferências ambientais (precipitações pluviométricas, geadas, umidade relativa) esperava-se uma alta infestação de afídeos na cultura implantada, pois segundo Zúñiga (1982), o elevado índice pluviométrico e a ocorrência de geadas fortes contribuem para a baixa infestação de afídeos na cultura de trigo.

Observou-se que durante o início do espigamento, os pulgões migraram das folhas para as espigas. A densidade média foi de apenas 0,47 afídeo/planta, atingindo no pico 1,85 afídeo/planta. Esta densidade pode ser considerada baixa, pois o Instituto Agronômico do Paraná (2003) recomenda o controle de pulgões a partir de 10 indivíduos/afilho ou espiga. Esse resultado ocorreu, possivelmente, devido à ação dos parasitóides e predadores que foram beneficiados pelo ambiente favorável na área da bacia hidrográfica (lavouras implantadas com as culturas de aveia, milho safrinha e pastagens), sendo que essa dinâmica, provavelmente, atuou preventivamente na redução dos afídeos, antes e durante o desenvolvimento da cultura do trigo. Anteriormente ao estabelecimento do programa de controle biológico dos afídeos do trigo, no Rio Grande do Sul registrou-se a ocorrência de 150 afídeos de $S$. avenae na espiga (KOBER, 1972), e no Paraná Pimenta e Smith (1976) assinalaram picos populacionais de 255,3 afídeos/planta.
É importante salientar que desde o início da infestação até a fase de grão leitoso ocorreu a presença de adultos alados, parasitóides e predadores na cultura, resultados que estão de acordo com os obtidos por Rabbinge, Ankersmit e Pak (1979), em estudos realizados na Holanda.

Neste estudo a única espécie de parasitóide encontrada foi Aphidius colemani Viereck parasitando $S$. avenae. Esse parasitóide é considerado cosmopolita porque parasita uma grande diversidade de afídeos, como demonstrado por Sampaio, Bueno e Van Lenteren (2001) que verificaram Aphis gossypii Glover e Myzus persicae (Sulzer) como suscetíveis a $A$. colemani.

Sampaio (2004) relata que o parasitóide $A$. colemani foi coletado em 10 espécies hospedeiras, sendo encontrado parasitando pulgões de 8 gêneros, sendo 6 espécies da tribo Aphidini e 4 espécies da tribo Macrosiphini. Este provavelmente é originário do norte da Índia ou Paquistão e tem sido encontrado nas Américas do Norte e do Sul, Austrália e várias partes da Europa (GRASSWITZ, 1998).

Registrou-se a ocorrência de formas aladas, ápteras e ninfas de $S$. avenae parasitadas, o que corrobora Gonçalves-Gervásio et al. (2001), segundo os quais $A$. colemani parasita todos os estádios dos 
afídeos, exceto os ovos, não demonstrando preferência por nenhum deles. $\mathrm{O}$ afídeo mumifica, ou seja, é morto pouco antes da larva do parasitóide empupar.

Esta espécie de parasitóide provavelmente foi favorecida pelas condições antrópicas, pois Tavares (1991), em "varredura" na vegetação de ambiente de mata, e ambiente de vegetação urbana encontrou nesses locais exemplares de A. colemani, e ainda, observou que parasitavam a maior parte dos afídeos. Além disso, acredita-se que $A$. colemani fazia parte da composição faunística do Brasil, antes do início do programa de controle biológico dos afídeos dos cereais no Rio Grande do Sul pois, constava da lista das espécies citadas de parasitóides de afídeos, juntamente com Diaeretiella rapae (McIntosh) e Lysiphlebus testaceipes (Cresson) (PIMENTA; SMITH, 1976; ZÚÑIGA, 1982).
Além disso, A. colemani foi introduzido no Chile (VAN DEN BOSCH, 1977), no Rio Grande do Sul pela Embrapa- Trigo no período de 1978 a 1980 (SALVADORI; SALLES, 2002) e na região Oeste do Paraná, em 1984 a 1985, segundo contatos realizados com Cecconello.

Considerou-se no presente estudo eficiente a ação do parasitismo no controle dos pulgões pois, concomitantemente à elevação da população de afídeos, cresceram os níveis de parasitismo de $A$. colemani, atingindo o pico populacional em meados de agosto, com parasitismo de $37 \%$ na temperatura média de $16^{\circ} \mathrm{C}$, ocorrendo sua diminuição gradativa nas quatro semanas seguintes (Figura 3 ). Resultados semelhantes foram obtidos por Sampaio (2004), que observou a maior incidência de parasitóides de pulgões (64\% dos pulgões parasitados) na época de menores temperaturas (julho a outubro).

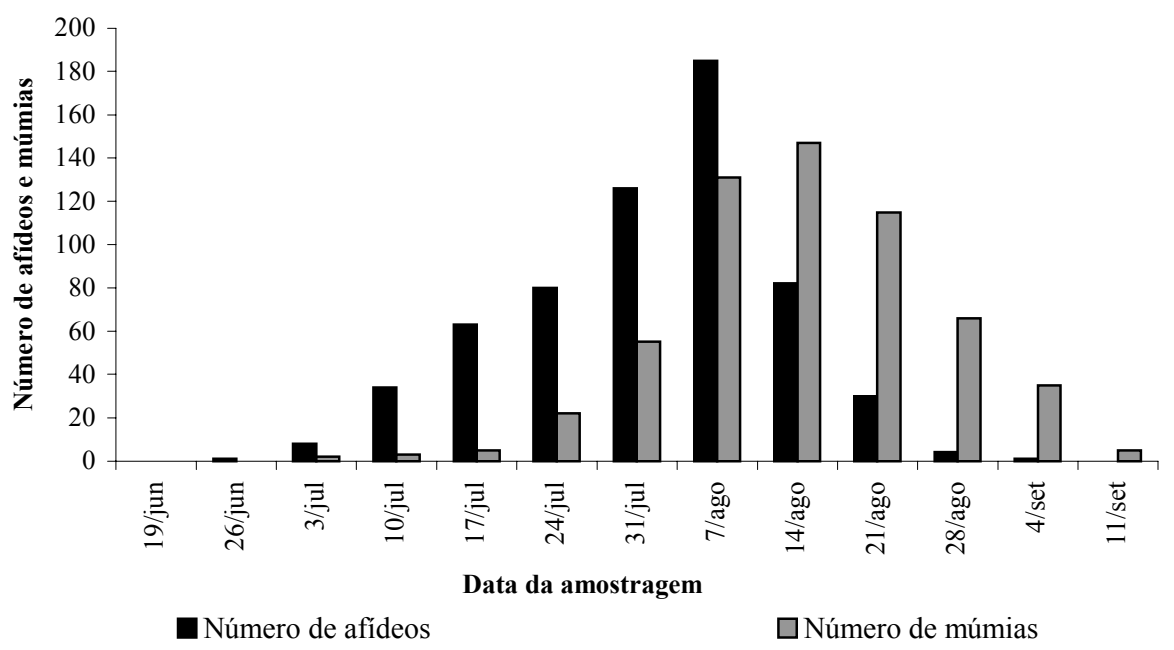

Figura 3. Flutuação populacional de Sitobion avenae e múmias, de junho a setembro de 2003, na cultura do trigo em Medianeira, PR.

A temperatura mínima influenciou verificando-se maior número (147 múmias) período significativamente a população de parasitóides de 7 a 14 de agosto (Tabela 2) (Figura 4). conforme a análise de correlação $(\mathrm{r}=-0,60181)$, 


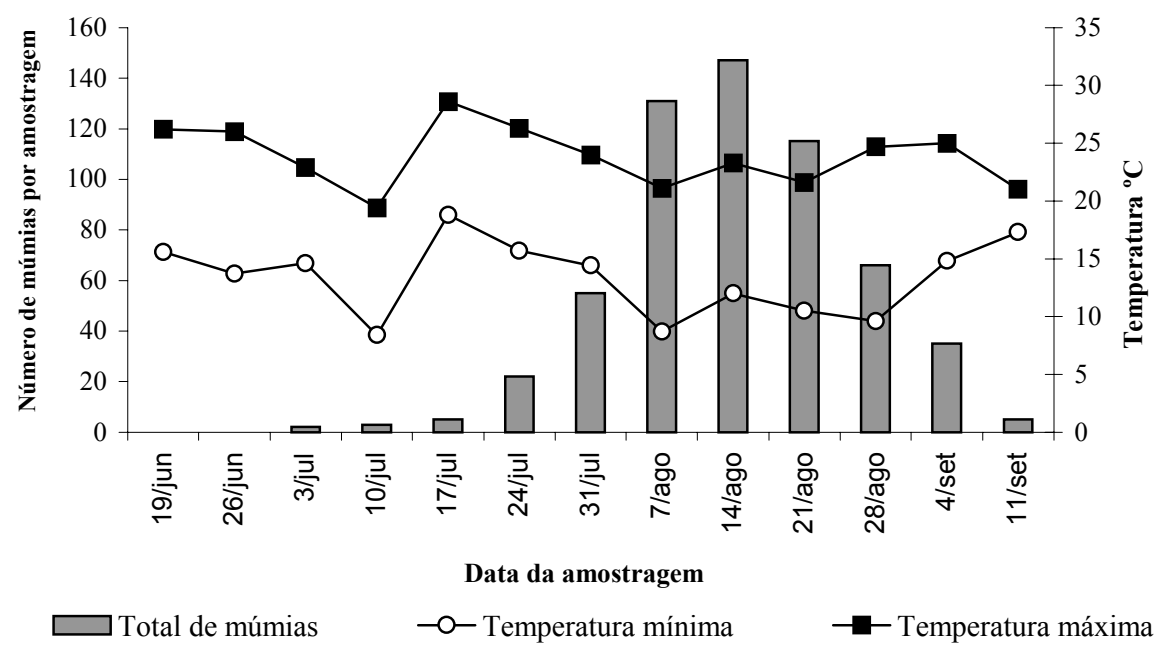

Figura 4. Flutuação populacional de múmias e as médias semanais de temperatura máxima e mínima, de junho a setembro de 2003, na cultura de trigo em Medianeira, PR.

Ainda sobre a influência da temperatura, Sampaio (2004) ressalta que uma diminuição da ocorrência de $A$. colemani foi detectada, na região Sudeste do Brasil, nos meses de dezembro a fevereiro, os quais coincidem com temperaturas mais altas e diminuição na abundância da maioria das espécies de pulgões. A menor ocorrência pode ser atribuída ao efeito direto da temperatura sobre o parasitóide ou sobre seus hospedeiros, ou ainda, ao efeito competitivo com outras espécies de parasitóides.

A umidade relativa foi baixa e variou pouco no período das amostragens das múmias (32 a 40\%), sendo que não influenciou significativamente a população de parasitóides (Tabela 2).

Do total das 586 múmias coletadas, em 199 delas emergiram parasitóides (34\%), em 172 hiperparasitóides $(29,4 \%)$ e de 215 nada emergiu $(36,6 \%)$ (Tabela 3). Estes valores diferem dos observados por Pimenta e Smith (1976) no Paraná, pois de um total de 146 múmias coletadas na cultura do trigo, obtiveram $91,6 \%$ de hiperparasitas e apenas $8,4 \%$ de emergência de parasitóides primários.

Após a coleta das múmias, observou-se com temperatura média de $23^{\circ} \mathrm{C}$ que no período de $10 \mathrm{a}$ 12 dias emergiram os parasitóides e em 15 a 18 dias os hiperparasitóides. Este período de emergência está em conformidade com os obtidos por Bueno (2000), que verificou que na temperatura de $21^{\circ} \mathrm{C}$ e, tendo M. persicae como hospedeiro de A. colemani, este apresentou um período de desenvolvimento médio de 14,2 dias e nas temperaturas de 18 e $22^{\circ} \mathrm{C}$, em Aphis gossypii Glover, esse período foi de 11,2 e 8,3 dias, respectivamente. No entanto, GonçalvesGervásio et al. (2001) observaram que da formação da múmia até a emergência de adulto de $A$. colemani decorreram em média 5,65 dias e a porcentagem de emergência foi em média de $75,5 \%$ à temperatura de $21 \pm 2^{\circ} \mathrm{C}$, umidade relativa de $70 \%$ e $12 \mathrm{~h}$ de fotofase.

Porém, Sampaio, Bueno e Van Lenteren (2001) registraram níveis mais altos de emergência de $A$. colemani com $86 \%$ para ninfas de $2^{\circ}$ e $3^{\circ}$ ínstares em $A$. gossypii e $81 \%$ para $M$. persicae. Ainda sobre a emergência deste parasitóide, Sampaio et al. (2003) verificaram porcentagem de emergência de $90 ; 94,2 ; 93,3 ; 85,8$ e $27,5 \%$, respectivamente, nas temperaturas de $16,19,22,25$ e $28 \pm 1^{\circ} \mathrm{C}$, não ocorrendo formação de múmias a partir de $31^{\circ} \mathrm{C}$, sendo que Sampaio (2004) destaca que a temperatura de $22^{\circ} \mathrm{C}$ é a mais adequada para o desenvolvimento de $A$. colemani. 
Tabela 3. Número de total de múmias de Sitobion avenae coletadas semanalmente em 100 plantas de trigo e número e porcentagem de parasitóides primários, hiperparasitóides e indivíduos não identificados emergidos das múmias, de junho a setembro de 2003, Medianeira, PR.

\begin{tabular}{|c|c|c|c|c|c|c|c|}
\hline Semana & Total de múmias & Parasitóides & & Hiperparasi & & Não identifi & \\
\hline & $\mathrm{N}^{\mathrm{o}}$ & $\mathrm{N}^{\mathrm{o}}$ & $\%$ & $\mathrm{~N}^{\mathrm{o}}$ & $\%$ & $\mathrm{~N}^{\mathrm{o}}$ & $\%$ \\
\hline 19/jun & 0 & 0 & 0 & 0 & 0 & 0 & 0 \\
\hline 26/jun & 0 & 0 & 0 & 0 & 0 & 0 & 0 \\
\hline 03/jul & 2 & 1 & 50 & 1 & 50 & 0 & 0 \\
\hline 10/jul & 3 & 2 & 67 & 1 & 33 & 0 & 0 \\
\hline 17/jul & 5 & 4 & 80 & 0 & 0 & 1 & 20 \\
\hline 24/jul & 22 & 10 & 46 & 6 & 27 & 6 & 27 \\
\hline 31/jul & 55 & 27 & 49 & 8 & 15 & 20 & 36 \\
\hline 07/ago & 131 & 74 & 56 & 34 & 26 & 23 & 18 \\
\hline 14/ago & 147 & 58 & 39 & 41 & 28 & 46 & 33 \\
\hline 21/ago & 115 & 16 & 14 & 43 & 37 & 58 & 49 \\
\hline 28/ago & 66 & 5 & 8 & 26 & 39 & 35 & 53 \\
\hline $04 /$ set & 35 & 1 & 3 & 11 & 31 & 23 & 66 \\
\hline $11 /$ set & 5 & 1 & 20 & 1 & 20 & 3 & 60 \\
\hline Total & 586 & 199 & 34 & 172 & 29,4 & 215 & 36,6 \\
\hline
\end{tabular}

As cápsulas contendo as múmias das quais nada emergiu, foram acondicionadas em recipientes escuros, armazenadas por um período de 70 a 80 dias, quando então, se realizou a dissecação. Das 215 múmias de onde nada emergiu, observou-se que em $47 \%$ havia larvas em diapausa, podendo ser tanto de parasitóides quanto de hiperparsitóides e nas 53\% restantes as larvas estavam mortas. Estes resultados, provavelmente ocorreram devido ao fato das múmias terem sido acondicionadas em recipientes escuros, ocasionando o estado de diapausa dos parasitóides. Resultados semelhantes foram obtidos por Zúñiga (1982), que de 2036 múmias de $S$. avenae dissecadas, 1224 (60,1\%) continham larvas vivas do quarto instar de parasitóides, caracterizando o estado de diapausa.

Ainda sobre a formação e a emergência de $A$. colemani, Sampaio (2004) verificou índices altos de emergência até a temperatura de $25^{\circ} \mathrm{C}$, diminuindo a $28^{\circ} \mathrm{C}$, principalmente pela não ocorrência de emergência de parasitóide nesta temperatura, que mesmo completando o ciclo biológico, vários parasitóides não emergiram, apresentando-se mortos no interior das múmias.

No presente estudo, as cápsulas gelatinosas contendo as múmias ficaram expostas às condições ambientais, sendo que em algumas horas do período matutino, as mesmas foram submetidas à ação dos raios solares, fato que pode ter causado a elevação da temperatura, interferindo no desenvolvimento e ocasionado a morte das larvas contidas nas múmias.

Verificou-se também, a existência de interação significativa entre pulgões e parasitóides primários $(\mathrm{r}=0,60401)$, o que influenciou significativamente a redução populacional dos pulgões pois uma semana após o surgimento dos primeiros afídeos no campo foram coletados os primeiros pulgões parasitados (múmias), ocorrendo um aumento gradativo do parasitismo com o aumento da população do hospedeiro, atingindo o pico populacional na semana seguinte ao pico dos afídeos, totalizando-se um índice de $95 \%$ de parasitismo (Tabela 4) (Figura 5). Esses resultados estão em conformidade com Ruth et al. (1975), que verificaram parasitismo de L. testaceipes sobre Schizaphis graminum (Rondani) na cultura do sorgo nos Estados Unidos, cinco dias após o surgimento dos pulgões, enquanto no Brasil, Fernandes et al. (2000) verificaram a ocorrência de duas espécies de parasitóides Aphelinus gossypii Timberlake e L. testaceipes parasitando A. gossypii na cultura do algodão durante todo o ano, mas com maior número nos meses de maio a novembro. 
Tabela 4. Número de total de pulgões Sitobion avenae, número total de múmias e percentual de parasitismo, de junho a setembro de 2003, Medianeira, PR.

\begin{tabular}{ccc}
\hline Número total de pulgões & Número total de múmias & Total de parasitismo \\
${$\cline { 1 - 3 }$^{\circ}} }$ & $\mathrm{~N}^{\mathrm{o}}$ & $\%$ \\
614 & 586 & 95 \\
\hline
\end{tabular}

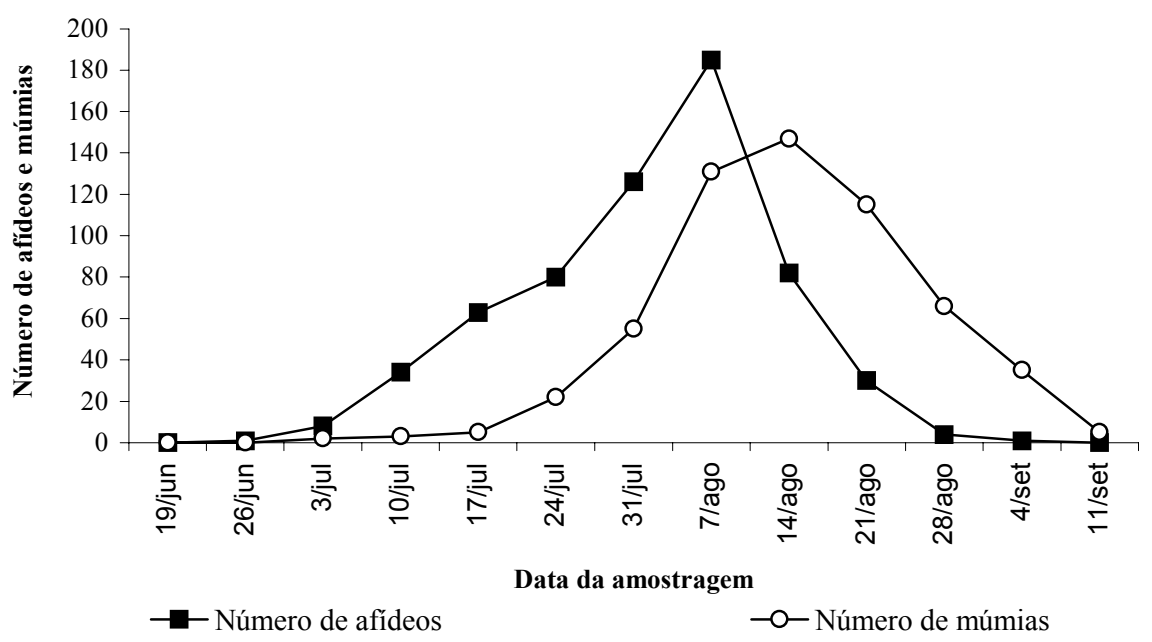

Figura 5. Flutuação populacional de Sitobion avenae e múmias ocorridos de junho a setembro de 2003, na cultura do trigo em Medianeira, PR.

No entanto, anteriormente à liberação dos parasitóides no Brasil, Pimenta e Smith (1976) registraram baixos níveis de parasitismo em $S$. avenae em Ponta Grossa e Colombo, PR. Em Colombo, as múmias surgiram em meados de agosto, nunca chegando a altas porcentagens de parasitismo $(8,4 \%)$, mesmo quando sua população estava no auge. Em Ponta Grossa, o parasitismo também foi baixo $(6,8 \%)$, iniciou em setembro e terminou em outubro. No início da liberação dos parasitóides Zúñiga (1982) obteve índices de parasitismo mais altos (21\%) encontrando como primeiros exemplares $A$. colemani, em agosto parasitando $S$. avenae e Metopolophium dirhodum (Walker), atingindo o pico máximo em meados de outubro em lavouras de trigo em Espumoso, RS.

Observou-se a ocorrência de hiperparasitismo, com a presença dos primeiros indivíduos simultaneamente aos parasitóides, ocorrendo um aumento gradativo, correspondente ao aumento do número de parasitóides, atingindo o pico máximo no final de agosto, com 43 indivíduos (Figura 6).

Os hiperparasitóides encontrados foram Pachyneuron sp., Dendrocerus sp., Alloxysta sp., Tetrastichus sp. e Syrphophagus sp., sendo que a razão sexual e os respectivos percentuais de ocorrência de cada uma dessas espécies estão representadas na Tabela 5. Estes dados concordam com os registrados por Zúñiga (1982), que encontrou em maior quantidade os hiperparasitas Alloxysta sp., Dendrocerus sp., Tetrastichus sp., Pachyneuron sp., no período de 1978 e 1979, na cultura do trigo, no Rio Grande do Sul. Contudo, diferente ao aqui observado, os hiperparasitóides em $S$. avenae apareceram no final de cada safra, não prejudicando deste modo a ação dos parasitóides primários. 


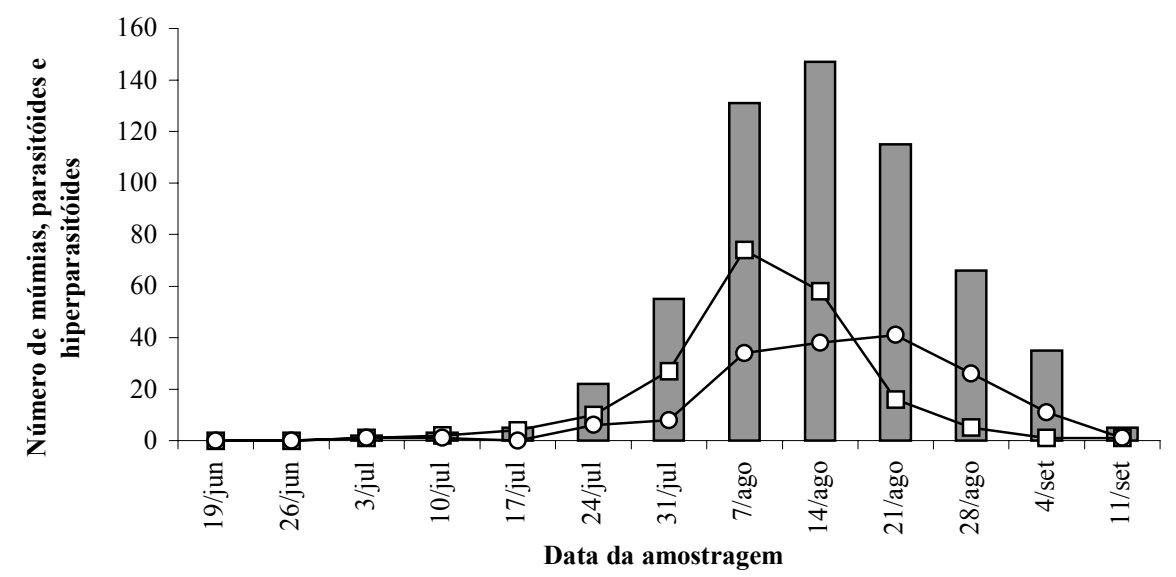

$\square$ Total de múmias $\quad-\square-$ Número de parasitóides $\quad$ - $\quad$ Número de hiperparasitóides

Figura 6. Interação entre o número de múmias, parasitóides e hiperparasitóides ocorridos de junho a setembro de 2003 , na cultura do trigo em Medianeira, PR.

Tabela 5. Ocorrência de hiperparasitismo em Aphidius colemani com o total de machos e fêmeas de hiperparasitóides e razão sexual de junho a setembro de 2003, coletados em trigo em Medianeira, PR

\begin{tabular}{lccccc}
\hline Hiperparasitóides & Fêmeas & Machos & Total & Porcentagem & Razão sexual \\
\hline Pachyneuron sp. & 48 & 27 & 75 & 43,3 & $1,7: 1$ \\
Dendrocerus sp. & 39 & 28 & 67 & 38,9 & $1,4: 1$ \\
Alloxysta sp. & 15 & 7 & 22 & 12,8 & $2,1: 1$ \\
Tetrastichus sp. & 1 & 5 & 6 & 3,3 & $0,2: 1$ \\
Syrphophagus sp. & 1 & 1 & 2 & 1,7 & $1: 1$ \\
\hline
\end{tabular}

Estes parasitóides foram também encontrados em diferentes percentuais de ocorrência por Pimenta e Smith (1976) que registraram em Ponta Grossa e Colombo, PR um total de 143 múmias coletadas parasitadas por A. colemani, com $91,6 \%$ de hiperparasitismo, com predominância de Alloxysta sp., seguida por Pachyneuron sp., Aphidencyrtus sp. e Dendrocerus sp. Entretanto, os autores consideraram baixos os índices de parasitismo primário, sugerindo que esses resultados, em relação ao parasitismo primário, decorreram dos altos índices de hiperparasitismo ocorridos no ano anterior.

Segundo Tavares (1991), os hiperparasitóides Dendrocerus sp. e Syrphophagus sp. não eram citados para o Brasil, enquanto que Alloxysta sp. e Pachyneuron sp. são de ocorrência bem conhecida na América do Sul, sendo que Alloxysta sp. está associado $D$. rapae e $A$. colemani.
Sendo o hiperparasitismo um elemento importante dos mecanismos da comunidade para a manutenção das populações dos parasitóides dentro de certos limites (ZÚÑIGA, 1982), observou-se no presente estudo, que o hiperparasitismo interferiu significativamente $(\mathrm{r}=0,70669)$ sobre a população de parasitóides primários, contribuindo para o seu controle (Tabela 2). Esta correlação significativa pode estar relacionada ao fato dos parasitóides primários e hiperparasitóides terem surgido juntos na cultura, sendo que o parasitóide primário atingiu população máxima em meados de agosto, vindo a diminuir gradativamente; enquanto o hiperparasitóide continuou crescendo, atingindo pico no final de agosto, quando o número de parasitóides já era muito baixo. Estes resultados estão de acordo com Morris, Müller e Godfray (2001), que registraram em trabalho de campo, nas culturas de ervilha e fava no sul da 
Inglaterra, a presença de Dendrocerus sp. parasitando A. rhopalosiphi sobre $S$. avenae, contribuindo para a redução dos parasitóides primários.

Registrou-se também, neste estudo, a presença de predadores, besouros Eriopis connexa (Germar), Cycloneda sanguinea (L.) e Hippodamia convergens Guérin Mènevilli (Coccinellidae) e do neuróptero Chrysoperla externa (Hagen) (Chrysopidae), associados aos afídeos $S$. avenae (Tabela 6). Também no Paraná, Pimenta e Smith (1976) coletaram em plantas de trigo, indivíduos das famílias Coccinellidae e Chrysopidae, associados aos afídeos nos meses de agosto, setembro e outubro, sendo que o maior número ocorreu em outubro. Em Minas Gerais, Mendes et al. (2000) verificaram a ocorrência de predadores na cultura da alfafa, com $58,2 \%$ de Coccinellidae e $0,7 \%$ de Chrysopidae sendo que os Coccinellidae foram os que apresentaram o maior número de espécies, com 49,6\% de $C$. sangüínea, iniciando o aparecimento em maio, crescendo gradualmente e atingindo o pico em junho, coincidindo com o aumento na população de afídeos.

Tabela 6. Número total dos predadores identificados semanalmente em um metro linear nas parcelas, de trigo de junho a setembro de 2003, Medianeira, PR.

\begin{tabular}{lcccc}
\hline Semana & $\begin{array}{c}\text { Eriopis } \\
\text { connexa }\end{array}$ & $\begin{array}{c}\text { Cycloneda } \\
\text { sanguinea }\end{array}$ & $\begin{array}{c}\text { Hippodamia } \\
\text { convergens }\end{array}$ & $\begin{array}{c}\text { Chrysoperla } \\
\text { externa }\end{array}$ \\
\hline 19/jun & 0 & 0 & 0 & 0 \\
$26 /$ jun & 0 & 0 & 0 & 0 \\
03/jul & 0 & 0 & 0 & 3 \\
$10 /$ jul & 0 & 1 & 0 & 3 \\
17/jul & 1 & 1 & 0 & 6 \\
$24 /$ jul & 3 & 0 & 1 & 10 \\
$31 /$ jul & 0 & 3 & 1 & 8 \\
07/ago & 1 & 1 & 9 \\
14/ago & 1 & 1 & 9 \\
$21 /$ ago & 1 & 0 & 5 \\
28/ago & 2 & 0 & 0 & 1 \\
04/set & 1 & 0 & 0 & 1 \\
11/set & 0 & 0 & 0 & 0 \\
\hline Total & 0 & 8 & 4 & 55 \\
\hline
\end{tabular}

Embora tenha se registrado neste estudo a ocorrência de apenas uma espécie de parasitóide considera-se importante a continuidade de estudos buscando-se verificar as espécies estabelecidas na região oeste do Paraná, bem como seus aspectos ecológicos.

\section{Conclusões}

A única espécie de afídeo encontrada foi Sitobion avenae e o parasitóide primário foi Aphidius colemani. Constataram-se os gêneros de hiperparasitóides Pachyneuron sp., Dendrocerus sp., Alloxysta sp., Tetrastichus sp. e Syrphophagus aphidivorus. Verificou-se também, a presença de predadores das famílias Coccinellidae e Chrysopidae.

O crescimento da população de afídeos foi influenciado significativamente pela umidade relativa do ar, enquanto que a população de parasitóide foi influenciada pela temperatura e pela densidade populacional dos pulgões. 
Aspectos ecológicos do Aphidius colemani Viereck (Hymenoptera: Aphidiidae) sobre a população...

Os picos populacionais de afídeos e de parasitismo foram verificados quando as plantas do trigo estavam no estádio fenológico de floração.

O parasitismo de A. colemani atingiu $95 \%$ do número total de $S$. avenae, e considerou-se eficiente o controle dos afídeos pelo parasitóide.

\section{Agradecimentos}

As Dras. Profas. Sonia M. N. Lazzari e Regina C. Zonta de Carvalho do Departamento de Zoologia da Universidade Federal do Paraná, pela identificação dos afídeos.

\section{Referências}

APABLAZA, H. J. U.; TISKA, V. V. Poblaciones de afidos (Homoptera: Aphididae) en trigo de la zona central Chilena. Revista Chilena de Entomologia, Santiago, v.7, p.173181, 1973.

BUENO, V. H. P. Desenvolvimento e multiplicação do parasitóide do gênero Aphidius Nees. In: BUENO, V. H. P. (Ed.). Controle biológico de pragas: produção massal e controle de qualidade. Lavras: UFLA, 2000. p.137-159.

FEECKES, W. De tarwe en haar milieu. Verslagen Technische Tarwe, Groningen, v.12, p.560-561, 1941.

FERNANDES, A. M. V.; FARIAS, A. M. I.; FARIA, C. A.; TAVARES, M. T. Ocorrência de Aphelinus gossypii Timberlake (Hymenoptera: Aphelinidae) parasitando Aphis gossypii Glover (Hemiptera: Aphididae) em algodão no Estado de Pernambuco. Anais da Sociedade Entomológica do Brasil, Jaboticabal, v.29, n.4, p.831-834, 2000.

GASSEN, D. N. Parasitos, patógenos e predadores associados à cultura do trigo. Passo Fundo: Embrapa, 1986. (Circular Técnica).

GASSEN, D. N.; TAMBASCO, F. J. Controle biológico dos pulgões do trigo no Brasil. Belo Horizonte: EMBRAPA, 1983a. (Informe Agropecuário)

Manejo integrado de pragas em trigo. Belo Horizonte: EMBRAPA, 1983b. (Informe Agropecuário)

GONÇALVES-GERVÁSIO, R. C. R.; SANTA-CECILIA, L. V.C.; CARVALHO, V. L.; FOUREAUX, L. V.; KATO, C. M.; CAMPELO, M. G. Efeito da idade de fêmeas Aphidius colemani Viereck (Hymenoptera:Aphidiidae) no parasitismo de Schizaphis graminum (Rondani) (Homoptera: Aphididae). Revista Ceres, Viçosa, v.48, p.277-283, 2001.
GRASSWITZ, T. R. Effect of adult experience on the hostlocation behavior of the aphid parasitoid Aphidius colemani Viereck (Hymenoptera:Aphidiidae). Biological Control, Orlando, v.12, p.177-181, 1998.

INSTITUTO AGRONÔMICO DO PARANÁ. Informações Técnicas Para as Culturas do Trigo e Triticale no Paraná. Londrina: IAPAR, 2003.

KOBER, E. A. M. Combate aos pulgões que atacam o trigo. Porto Alegre: Secretaria de Agricultura do Estado do Rio Grande do Sul. 1972. (Comunicado Técnico).

KRING, T. J.; KRING, J. B. Aphid fecundity, reproductive longetivy, and parasite development in the, Schizaphis graminum (Rondani) (Homoptera: Aphididae) Lysiphlebus testaceipes (Cresson) (Hymenoptera: Braconidae) System. Canadian Entomologist, Ottawa, v.120. p.1079-1083, 1988.

MENDES, S.; CERVIÑO, M. N.; BUENO, V. H. P.; AUAD, A. M. Diversidade de pulgões e de seus parasitóides na cultura de alfafa. Pesquisa Agropecuária brasileira, Brasília, v.35, p.1305-1310, 2000.

MORRIS, R. J.; MÜLLER, C. B.; GODFRAY, H. C. J. Field experiments testing for apparent competition between primary parasitoids mediated by secondary parasitoids. Journal of animal ecology, Oxford, v.70, p.301-309, 2001.

PIMENTA, H. R.; SMITH, J. G. Afideos, seus danos e inimigos naturais em plantações de trigo (triticum sp.) no estado do Paraná. Curitiba: Organização das Cooperativas do Estado do Paraná, 1976. (Relatório Técnico).

RABBINGE, R.; ANKERSMIT, G. W.; PAK, G. A. Epidemology and simulation of population development of Sitobion avenae in winter wheat. Netherlands Journal of Plant Pathology, Wageningen, v.85, p.197-220, 1979.

RUTH, W. E.; MCNEW, R. W.; CAVES, D. W.; EIKENBARY, R. D. Greenbugs (Hom.: Aphididae) forced from host plants by Lysiphlebus testaceipes (Hym.; Braconidae), Entomophaga, Paris, v.20, p.65-71, 1975.

SALVADORI, J. R. Controle biológico de pulgões de trigo: sucesso que perdura. Passo Fundo: Embrapa, 1999. (Comunicado Técnico).

SALVADORI, J. R.; SALLES, A. B. Controle biológico dos pulgões do trigo. In: PARRA, J. R. P.; BOTELHO, P. S. M.; FERREIRA, B. S. C.; BENTO, J. M. S. (Ed.), Controle biológico no Brasil: parasitóides e predadores. São Paulo: Manole, 2002. Cap.26, p.427-443.

SAMPAIO, M. V. Bioecologia de Aphidius colemani Viereck, 1912 (Hymenoptera: Braconidae, Aphidiinae) 2004. Tese (Doutorado) - Universidade Federal de Lavras, Lavras. 
SAMPAIO, M. V.; BUENO, V. H. P., RODRIGUES, S. M. M.; SOGLIA, M. C. M. Desenvolvimento de Aphidius colemani Viereck (Hymenoptera: Aphidiidae) em diferentes temperaturas. In: SIMPÓSIO DE CONTROLE BIOLÓGICO, 8., 2003, São Pedro, Anais... Piracicaba: ESALQ/USP, 2003.

SAMPAIO, M. V.; BUENO, V. H. P.; VAN LENTEREN, J. C. Preferência de Aphidius colemani Viereck (Hymenoptera:Aphidiidae) por Myzus persicae (Sulzer) e Aphis gossypii Glover (Hemiptera: Aphididae). Neotropical Entomology, Londrina, v.30, n.4, p.655-660, 2001.

TAVARES, M. T. Estudo das interações "Planta/Afideo/ Parasitóide e Hiperparasitóide" em ambientes naturais e antrópicos. 1991. Dissertação (Mestrado) - Universidade Federal de São Carlos, São Carlos.
VALENCIA, L.; TRILLOS, O. Control integrado de plagas de Papa. Bogotá, Colômbia: Centro Internacional de La Papa, 1986.

VAN DEN BOSCH, R. Informe de la segunda visita a Chile como consultor para el programa de control biologico e integrado de los afidos de los cereales. Investigaciones Agropecuarias, La Aurora, Guatemala, v.9, p.16-24, 1977. ZÚÑIGA, E. S. Controle biológico dos afídeos do trigo (homoptera: Aphididae ) por meio de parasitóides no Planalto Médio do Rio Grande do Sul. 1982. Tese (Doutorado em entomologia) - Universidade Federal do Paraná, Curitiba. 